\title{
ZAGZEBSKI ON MODELS OF REVELATION
}

\section{JACEK WOJTYSIAK}

\author{
John Paul II Catholic University of Lublin
}

From the numerous themes present in a deep and inspiring book by Linda Zagzebski, Epistemic Authority, I would like to address some problems related to the model of revelation (chap. 9, sec. 3.2, pp. 191-199). ${ }^{1}$ It is particularly important for theologians and followers of the religions, such as Judaism, Christianity and Islam, which 'have in common a revelation from God at a time in the past' (p. 192). Both theologians and ordinary believers want to understand the content of the revelation and guarantee its inviolable transmission through generations. A philosopher of religion, however, asks whether it is at all possible for such a revelation to occur, and if so, how it is to be recognized and in what ways it may be accessible to a great number of people over a very long period of time in widely varying circumstances' (p. 191). Zagzebski discusses three out of a variety of models of revelation conceived of as a specific kind of communication between God and the human being ('communication between God and me' - p. 191). Using her key words, let us call them, respectively: the chain model, the experience model, and the high point (or the state of perfection) model.

\section{ASSUMPTIONS}

Before I examine, in discussion with Linda Zagzebski, the mentioned models, I will reconstruct the assumptions that she accepted and that, consequently, affected her choice, presentation and evaluation of those models. (Zagzebski clearly sympathizes with the last one). In my opinion,

\footnotetext{
${ }^{1}$ If not indicated otherwise, all page numbers refer to the discussed book by Linda Trinkaus Zagzebski (2012).
} 
those assumptions - and their equivalents presented and defended in various parts of her book - come down to the following:

The assumption of historicity: God's revelation took place at a definite moment or period in the history of humankind and is transmitted or updated in the times that follow it. (This assumption does not exclude the existence of non-historical revelation, but leaves it out of the scope of analysis.)

The assumption of communality: The recipient of revelation is a member of a definite community, of a certain We, within which a revelation takes place and is transmitted.

The assumption of the indispensability of authority: No human being can acquire correct beliefs on divine matters, or lead a proper religious life, relying exclusively on herself, in a cognitive isolation (or independence) from beliefs and exemplars of life of the community that is a partner in a revelation.

The assumption of the test of conscientious judgment: The condition of a given person's justified acceptance of a given religious community authority (as a partner or a bearer of a revelation) is the person's conscientious judgment that if she engages in the beliefs and practices of this community - instead of forming them on her own - the chances that their result will survive her conscientious selfreflection will increase. ${ }^{2}$

I believe that a good model of revelation should not only agree with the listed assumptions, but should also provide more specific criteria to recognize a revelation and to correctly choose a religious authority from competing candidates. As the author herself remarks, 'cases of competing authorities' (p. 111) and the fact 'of disagreement between communities' (p. 221), and especially between communal religious authorities, constitute one of the greatest challenges for epistemology (and especially for the epistemology of religion).

2 The first assumption appears clearly on pp. 190-192, the three others on pp. 199203. The assumption of communality seems a consequence of epistemic universalism, and the assumptions concerning authority are applications of the main argument of the book: in various areas of knowledge and life appear individuals or communities that are 'in a better position to get the truth [or other valuable ends] than I' (p. 111); if they pass the test of my conscientious self-reflection, 'I should follow the[ir] authority in that case' (p. 111). 


\section{THE CHAIN MODEL}

I believe that the chain model of revelation (CM) may be represented in agreement with Zagzebski's intentions (cf. pp. 193-194) - as a trichotomous structure:

(CM1) initiating event: God enters (at a definite historical time) in direct contact with the few chosen people (founders of religion, prophets, direct witnesses of divinity, etc.);

(CM2) multistage transmission: a result of the initiating event (in the form of stories, a set of rules, mystical poetry, etc.) 'is transmitted by oral or written testimony' to other people - first directly (eyewitnesses - their listeners or firsthand recipients), and later indirectly (firsthand recipients - secondhand recipients, etc.);

(CM3) integrating intention: in God's intention the initiating event (experience) contains important content that may be understood not only by an eyewitness, but also by all its $n$-hand recipients; due to this fact, all the recipients (regardless of when and where they live) can constitute one community - the community which, thanks to the acts of collective memory, continually makes available or updates the universal content of the initiating event. ${ }^{3}$

It seems obvious that the presented model agrees with the assumptions of historicity, communality and indispensability of authority. The only problem might at most be the fact of the privileged position of the initiating event participants. We should remember, however, that in the history of religions it is difficult to find isolated initiated events whose participants are deprived of the authoritative context of their own community. ${ }^{4}$ For instance, Moses stood before God as a representative of his community with its tradition and mission for the future. The membership of this community enabled him to identify the Revealing One as the God of his fathers, and His commands as the commands

${ }^{3}$ Point (CM3) is necessary to answer questions like: 'Why would it matter to us what a man called Abraham did, or that Moses had a religious experience in front of a burning bush if we are only the distant recipients of testimony about their contact with God?' (p. 193)

${ }^{4}$ We should rather speak of various types (conditioned by historical-communal contexts and connected to one another) of initiating events that differentiate the families of religions (e.g. the family of the Abrahamic religions), religions (e.g. Christianity), denominations (e.g. Methodism), and intra-confessional spiritual traditions (e.g. Franciscan spirituality in Catholicism). 
for the whole of Israel. Similar was the case of the Apostles who had initially interpreted the person of Jesus Christ in the context of the community of Israel, extending later its range under the influence of a new initiating event.

Let us assume the chain model and ask what more specific conditions must a given religious community, presumed to have been constituted by (CM1)-(CM3), meet to deserve a positive epistemic evaluation (according to the principle of the conscientious judgment test). In other words: When are we allowed to regard a given community as a reliable bearer of God's revelation or as a justified religious authority?

I believe that a person who attempts to judge the epistemic value of a given religious community should answer three questions:

(i) the question concerning (CM3): Does the community under evaluation proclaim contents comprehensible to its contemporaries and reveal universal truths about God and man?

(ii) the question concerning (CM2): Does the message transmitted by the community under evaluation accurately inform about the initiating event?

(iii) the question concerning (CM1): Has the initiating event (recounted in the message) actually been inspired by God?

I believe that a sympathetic interpretation of the contents proclaimed by the great world religions would allow an affirmative answer to the first question in almost all of the cases. ${ }^{5}$ In such a situation, the evaluation of a given religious community would depend on the answers to the remaining questions.

As for the second question, the advocates of the community under evaluation might refer to the so-called Expansion of Trust Principle:

'I have reason to trust those who are conscientiously trusted by those

I conscientiously trust.' (p. 97)

Indeed, in many religions their fundamental contents are transmitted on the basis of natural trust between numerous transmitters and recipients, conceived of as links in a multi-element chain. This trust is usually related to family ties: parents transmit their faith to children, the children to

\footnotetext{
${ }^{5}$ A less sympathetic or less open interpreter might judge that content from the vantage point of her prior (especially pre-religious) convictions concerning God, the world and values. Would such a person, however, need revelation, if she had known beforehand what exactly it should contain?
} 
their children, etc. Sometimes faith is acquired by people from outside these ties. This, however, is often related either to trust based on the emotion of admiration (cf. pp. 87-93), or to a rational analysis of the presumed authority's cognitive capacity. In each of these cases - as we can say, paraphrasing the Expansion of Authority Principles (p. 152) a person may be justified in believing that she has the proper access to the content of the initiating event, because she is justified in believing that it is not her, but the community or certain of its representatives who may have knowledge on this matter, and this community or its representatives are justified in believing that it is not them, but the first witness or witnesses (related to them) who have such knowledge. The access to the contents of the initiating event (experience) would then be guaranteed by the whole community as a chain of witnesses, initiated by the first witnesses. The links of this chain are bound together by the appropriate - most frequently based on trust or related emotions - acts of authority recognition.

Religious communities usually present themselves as faithful transmitters of the content of the initiating event. Their members have prima facie good reasons to believe in the message transmitted by their community. (Whom is the person born in this community to believe, if not her ancestors? And the one who joined the community basing on her own judgment - whom is she to believe, if not her ability to recognize authority?) The question arises, however, whether the community's message on the initiating event is sufficient to accept the claim to its divine origin. In this way we approach the problem (CM1) - the first and most important element of the chain model.

An adherent of the affirmative answer to the above question reasons more or less in the following way:

If I accept the testimony (coming from the first witnesses) of a given religious community on the initiating event, I should also accept its interpretation of this event (coming, explicitly or implicitly, from the first witnesses), including the interpretation that points to its divine origin; since the competences of the community (greatly exceeding my own) concern not only testimony transmission, but also its interpretation.

Let us call this approach the internal approach (IA), as it occurs most frequently in those who reason, as it were, from inside of a given 
community. Their adversaries - we will call them adherents of the external approach (EA) - might reason in the following way:

A religious community (and its first witnesses) is capable only of the transmission of information on the initiating event, but not of its interpretation; in that case I am allowed to accept the divine origin of the event only if I reach the belief that a description of this event (provided by the community and the first witnesses) contains such elements that if I had been its direct participant, I would have accepted (immediately or on further reflection) on the basis of those elements that the event had been inspired by God.

(EA) is most frequently used in religious apologetics. Not only do apologists wish to present the self-understanding of a given religious community, but, in the first place, they wish to present reasons that might induce a person from outside the community to accept its claims to divine origin. Among such reasons, Christian apologists give a special place to miracles. They usually claim that the trustworthy Christian message on the initiating events of Christianity includes information on miracles that confirm the divine origin of those events. For instance, Richard Swinburne (2008: 85-87) emphasizes that 'we need evidence of God's "signature" on the prophet's work', and that its key element is 'a violation of laws of nature'. Moreover, 'the particular violation must be of a kind which the culture in which the violation occurred would recognize as God's signature.' For Christians, such a sign would be the Resurrection of Christ presented in the trustworthy reports of the New Testament. ${ }^{6}$

I do not intend to evaluate here the claims of Christianity (or any other religion) to the authority in matters of divine revelation. The above analyses aimed only at showing that within the chain model it is possible to reconstruct how a given person may be justified in her belief about the access to divine revelation: this person may have good reasons to accept that a given community - through a chain of testimonies - reliably recounts the initiating event, which is of divine and universal character.

What would happen, however, when the mentioned person came across counter-reasons that oppose her belief? Those counter-reasons may be essentially reduced to the arguments supporting the thesis

${ }^{6}$ Cf. William L. Craig (2008: 333): 'If Jesus rose from the dead, then his claims are vindicated and our Christian hope is sure; if Jesus did not rise, our faith is futile [...]'. Cf. 1 Corinthians 15: 14-15. 
that - as Linda Zagzebski writes (p. 202) - reports on the so called initiating events 'have probably been distorted in multiple ways during the course of many centuries'. But how do we know this? An adherent of this thesis might refer either to the scientific knowledge concerning the times when the initiating events allegedly occurred, or point to the discrepancies between the relevant testimonies. Let us observe, however, that scientific knowledge concerning the past largely relies on the records of human testimonies on it. ${ }^{7}$ Therefore, the testimony of a community actually competes not with the pure knowledge of the past, but with other testimonies. All is thus reduced to the competition of testimonies. Every one of us, in various situations of life, must evaluate on one's own the reliability of the witnesses (sometimes competing) she encounters. This concerns also the religious sphere. It may happen that competing testimonies will induce an adherent of a given religion to abandon it or to convert to another one, or to correct her beliefs. However, it may also happen that those testimonies will be, in her opinion, too weak to change her beliefs, or that the testimony of her own community is more important to her. In the latter case she will continue believing in her original religion. ${ }^{8}$

\section{THE EXPERIENCE MODEL}

As Linda Zagzebski observes, the experience model - as opposed to the chain model - 'focuses on the recipient's experience rather than the original experience [(CM1)]' and reduces or 'minimizes the function of tradition [(CM2)] in preserving the past intact' (p. 194). In other words, in this model the nature of religious life does not consist in collective remembering of the remote initiating event, but amounts to the 'firsthand experience of the divine' (p. 194). This experience is shared by all the

$7 \mathrm{My}$ analysis omits the knowledge interpreted in the light of the principle of naturalism (claiming that no supernatural events can take place), because making such an assumption one cannot envisage any possibility of revelation.

${ }^{8}$ Let us remember that discrepancies between testimonies do not always concern essential issues. Besides, religious communities, especially those sharing common roots, dispute their interpretations of the message rather than its literal wording. It cannot also be excluded that the interpretations are complementary, and their multiplicity has been intended by the Revealing One who allows different ways of His revelation - according to the different cognitive capacities and spiritual needs of the revelation recipients. This issue merits a separate discussion, for instance, in the context of Zagzebski's pertinent example of the disagreement concerning the Holy Trinity (pp. 213, 219-221). 
confessors, and not only by God's chosen ones who, in the past, came into a direct contact with Him.

Then, how does it happen that individual religious persons, each of whom experiences God in the way limited 'to the experience of one person' (p. 202), form a community where a divine revelation acquires intersubjective validity? I suppose that it is so, because the experience model incorporates the principles of the chain model, giving them new functions. If this is true, one can say that in the experience model:

(EM1) the initiating event does not consist so much in an exclusive and immediate experience of God by the few people He elected, as it provides inspiration for all future experiences of God by many more people; it may also be the norm that enables evaluation whether a given experience is a proper experience of God;

(EM2) the function of the multistage transmission of the result of the initiating event (experience) does not consist so much in its faithful preservation for future generations, as in enabling still new experiences similar to the original one; ${ }^{9}$

(EM3) the integrating intention of God (the Holy Spirit) unites all believers into one community, but not on the principle of collective remembering, but thanks to the common content of their experiences, which in some way imitate the original experience.

As we can see, the above - and I believe the optimum - interpretation of the experience model presents it as a reformulation and expansion of the chain model. In consequence, the presently discussed model inherits the advantages of the previous model. Moreover it has an advantage absent in the chain model: it is the possibility of subjects' having additional reasons to accept a given religion, i.e. the subject can accept it not only on the basis of her conviction about the community's reliability in transmitting the testimony of the original revelatory event, but also on the basis of her personal experience of the universal contents of this event. The fact of this experience being shared by many people in different times and places makes it impossible to raise an objection of subjectivism and isolationism.

However, what will happen if a subject of an experience typical for a given religion meets a person with a radically different religious

${ }^{9}$ As Zagzebski writes (p. 197): in Christianity 'the transmission of the Gospels is the occasion by which the Holy Spirit produces faith as a first-hand relation to God'. 
experience? Then, like in the case of the competition of testimonies, the competition of experiences will occur. The difference between the two competitions consists in that, in the former case, the subject evaluates testimonies of others, while in the latter, she compares her own experiences to those of others. She can hardly be expected to give priority to someone else's experience over her own, to which she has a privileged first-person access. With William P. Alston (1993: 274), she might say:

'In the absence of any external reason for supposing that one of the competing [epistemic] practices [or experiences] is more accurate than my own, the only rational course for me is to sit tight with the practice of which I am a master and which serves me so well in guiding my activity in the world' and in the religion.

Finishing the analysis of the experience model, I would like to add that that some Christians emphasize the importance of the mentioned experience so strongly that they feel exempt from the epistemic concern for reasons to confirm the community's reliability in transmitting the testimony. I consider this an epistemic error. Without recognizing this reliability we cannot be justified in believing that our experiences are similar to the normative original experiences, and that the unity of different confessors' experiences is neither illusory nor accidental. Moreover, extreme interpretations of the experience model lead to the change in the concept of revelation, whose content - as I have already said - significantly includes (or ought to include) the factors of historicity, communality and authority.

\section{THE HIGH POINT MODEL}

The last model identifies divine revelation neither with the original experience (that is transmitted further), nor with subsequent experiences (inspired or regulated by the original one). In this model, revelation is identified (as Zagzebski puts it, p. 195, 197) with a certain 'way of understanding God': a given community acquired such a way of understanding in the period that it recognized as 'a high point' in its history. This way of understanding God is expressed in a collection considered as exemplary - of (oral and written) beliefs, stories, prayers, rites, practices, laws, commands, etc. We may say that - according to the model in question - God reveals Himself not so much in individual events or experiences, as in a self-understanding of a given religious 
community at the time when it was in a 'state of perfection' or mastery in the fulfilment of its activities. ${ }^{10}$

The merit of the high point model is its capacity, so that it can incorporate the previous models. Thus the mentioned exemplar of faith and practice of a given community may also include the story concerning the initiating event and 'the belief that the chain [of its transmission] is basically accurate' (p. 202) and unbroken. The exemplar may also include descriptions of paradigmatic religious experiences or other elements inspiring such experiences. Those factors are indeed very important for the life of religious communities; communities, however, transmit them in a wider context - in the context of once acquired, rich and compound wisdom.

An additional advantage of the discussed model is that it allows a wider range of reasons available to the subject who wishes to justify her acceptance of a given religion. The subject may thus refer not only to the reliability of a given community in transmitting the testimony of the initiating event or to her own or someone else's religious experiences, but also - or above all - to the cognitive and existential importance of the exemplar of beliefs and practices cultivated by the community. This is the case when the subject passes the conscientious judgment expressive of the following (or similar) content:

If I accept the exemplar of beliefs and practices proposed by a given religious community (instead of relying on another community or on myself only), my present and future convictions, feelings, experiences, actions, etc., will be coherently organized, justified or oriented, and 'will satisfy my future conscientious self-reflection' (p. 199).

The above judgement may be based either on the recognition of the quasi-moral characteristics of the very community (such as its longevity; the number of people who accepted its teachings and were not disappointed; multifarious fruitfulness, e.g. charitable or culturecreating, of its activities), or on the recognition of the epistemic value of beliefs it proclaims. In the latter case the judgment would be a kind of religious hypothesis, which - as the Polish logician Józef Bocheński

10 As examples Zagzebski gives 'the end of the biblical era' for Judaism and 'the Apostolic age' (and early post-Apostolic tradition) for (Catholic) Christianity. A secular analogy is the artisanal mastery achieved in 16th century by Venetian glassmakers whose technique has been imitated in Italian glassmaking until today (see p. 196). 
suggested (1965: 148) - plays in the religious life a role similar to that of a scientific hypothesis in reductive sciences. ${ }^{11}$

The above-presented advantage of the high point model cannot - in my opinion - undermine its double dependence on the chain model. The first dependence consists in that the exemplary collection of a community's beliefs (formed at its high point in the past) should necessarily, and not just facultatively, include a reliable story on the initiating event as a particular God's intervention, confirmed by special signs. Without His intervention, the emergence of this community as one inspired by God would be difficult to understand. Without it the community could offer its members or candidates nothing more than a system of human life wisdom - a system that would appear merely as one of the options on the market of competing worldviews.

The second dependence is conceptual. It is impossible to describe the essence of the high point model without using the principles of the chain model, as the former has also a trichotomous structure that results from the modification of the original model. The modification consists in that:

(HM1) the concept of the initiating event has been replaced by the concept of exemplary 'way of understanding God', formed at the time of a community's flourishing;

(HM2) the multistage transmission, mentioned in (CM2), refers now to the transmission not of the initiating event itself, but of the whole 'way of understanding God' as an exemplary system of beliefs and practices;

(HM3) the integrating (community-creating) intention of God is fulfilled not only by recalling the remote event, or producing or imitating similar experiences, but by applying the exemplar of faith

${ }^{11}$ Bocheński gave particular attention to two (fallible in their nature) ways of justifying religious beliefs: through the authority and through the religious hypothesis. In his theory of authority, he emphasized (among others) that every human authority is relativized to a given field, i.e. 'every authority [except God] is only an authority in a limited class of sentences, not for all sentences' (1965: 172). If so, one cannot suspect a cognitive dissonance in a person who accepts the authority of a given individual or community in some religious issues, and questions it in others. In turn the concept of the religious hypothesis is clarified by him in the following way: 'at a certain time of his life the subject begins to think that, if he does accept the BD [basic dogma] of a certain religion, then the whole of his experience will become organized and somewhat explained' (1965: 149). 
and practice to varying conditions of every believer's life - so that she can achieve 'a way of living contact with God' (pp. 197-198).

Let us observe that the above presentation of the high point model - as a structure based on (CM1)-(CM3) structure - emphasizes the necessary components of revelation mentioned earlier: historicity, communality and indispensable authority. However, the specific principles (HM1)(HM3) refer to different authorities or different layers of one authority: the authority of God, the authority of the exemplar of faith and of the experience of God (together with the authority of the initiating event transmission and the authority of its participants), the authority of the whole community, and the authority of institutions to which the 'responsibility for the authenticity [and updating] of tradition' (p. 198) has been ascribed. Examining the epistemic value of the authority conceived of in this way, it is necessary to consider more factors than in the case of less comprehensive models. All this renders the question of evaluating the revelatory claims, made by different religions, particularly complicated.

\section{CONCLUSION}

My analyses confirm Linda Zagzebski's belief that in looking for an adequate model of revelation, we need to go beyond the traditional chain model, as well as the model that attaches too much attention to experience. The high point model (or - as I would prefer to call it - the exemplary wisdom model) that she reconstructs actually seems to provide the most accurate description of the functioning of religion. Its greatest advantage is a very capacious understanding of revelation and authority. This capacity translates into a very wide range of reasons available to a subject to justify her choice of a certain religion (and also a wide range of problems she must consider in this context). It should be remembered, however, that the above model depends on the chain model in a significant way. In my opinion, the main epistemic concern of a person assessing the value of a given religion usually is - and should be - whether a given community speaks about facts and whether those facts consisted in the (continually updated) action of God. 


\section{BIBLIOGRAPHY}

Alston, William P. 1993. Perceiving God: The Epistemology of Religious Experience (Ithaca and London: Cornell University Press)

Bochenski, Joseph M. 1965. The Logic of Religion (New York: New York University Press)

Craig, William Lane. 2008. Reasonable Faith: Christian Truth and Apologetics (Wheaton, Illinois: Crossway Books)

Swinburne, Richard. 2008. Was Jesus God? (Oxford: Oxford University Press)

Zagzebski, Linda Trinkaus. 2012. Epistemic Authority: A Theory of Trust, Authority, and Autonomy in Belief (Oxford: Oxford University Press) 